\title{
An Analysis of Prosthodontic Research Productivity: Geographic, Economic, and Collaborative Perspective
}

\author{
Kathryn Thornton DMD, ${ }^{1}$ Damian J. Lee, DDS, ${ }^{2}$ Judy Chia-Chun Yuan, DDS, MS, ${ }^{2}$ \\ Kent L. Knoernschild, DMD, MS, ${ }^{3}$ Stephen D. Campbell, DDS, MMSc, ${ }^{4}$ \\ \& Cortino Sukotjo, DDS, MMSc, PhD $^{2}$ \\ ${ }^{1}$ Former Resident, Advanced Education Program in Prosthodontics, Department of Restorative Dentistry, University of Illinois at Chicago, College of
Dentistry, Chicago, IL. Current master student in Dental Public Health at School of Public Health, University of Michigan, Ann Arbor, MI
${ }^{2}$ Assistant Professor, Department of Restorative Dentistry, University of Illinois at Chicago, College of Dentistry, Chicago, IL
${ }^{3}$ Associate Professor, Director, Advanced Education Program in Prosthodontics, Department of Restorative Dentistry, University of Illinois at
Chicago, College of Dentistry, Chicago, IL
${ }^{4}$ Professor, Head of Restorative Dentistry, Department of Restorative Dentistry, University of Illinois at Chicago, College of Dentistry, Chicago, IL
}

Keywords

Prosthodontic literature; collaboration; economic status; globalization

\author{
Correspondence \\ Dr. Cortino Sukotjo, Department of \\ Restorative Dentistry, University of Illinois at \\ Chicago, College of Dentistry, 801 S. Paulina \\ St., Chicago, IL 60612. E-mail: \\ csukotjo@uic.edu
}

Accepted February 18, 2011

doi: 10.1111/j.1532-849X.2011.00776.x

\begin{abstract}
Purpose: This study evaluated the quantity of prosthodontic literature produced globally by continent in three prosthodontic journals over a 10-year period, 1998-2008. Prosthodontic research productivity relative to economic status of countries and collaboration among countries grouped by economic status was assessed.

Materials and Methods: Three peer-reviewed prosthodontic journals were used for the analysis of articles published in 1998, 2003, and 2008: The Journal of Prosthetic Dentistry, International Journal of Prosthodontics, and Journal of Prosthodontics. The country of every author listed for each included article was recorded. The number of articles published by each continent and each country was reported. Countries were grouped according to the World Bank economic classification system, and the number of articles published by each economic class was found.

Results: The majority of publications over the 10-year period were produced in Asia (Japan), Europe (Germany), and North America (USA). Productivity declined by $14.4 \%$ in high-income countries while it increased in upper middle-, lower middle-, and low-income countries. The majority of publications written by upper and lower middle- and low-income countries were independent works. Articles resulting from collaboration increased over time for all economic classes of countries.

Conclusions: The origins of prosthodontic literature are becoming more geographically and economically diverse, with increased contributions from Africa, Asia, and South America, and middle- and low-income countries between 1998 and 2008. Collaboration between high-income countries and the other economic group countries increased over time.
\end{abstract}

Oral disease is a global problem, affecting populations in both developed and developing countries. According to the World Health Organization, dental caries affects the majority of adults in most industrialized countries. ${ }^{1}$ Severe periodontitis has an estimated prevalence of $5 \%$ to $15 \%$ in most populations. ${ }^{1}$ Edentulism among adults aged 65 and over is prevalent worldwide, with reported rates ranging from $6 \%$ to $78 \%$ of populations in various countries. ${ }^{2}$ In developing countries, access to oral health services and availability of materials for dental treatment are frequently limited. ${ }^{2}$ Consequently, teeth are often extracted or left untreated in patients with pain. ${ }^{2}$ As discussed in a recent review, edentulism may be associated with several comorbidities, including diabetes, cardiovascular disease, asthma, and cancer. ${ }^{3}$ Oral health is an integral part of general health and should be addressed in both the developed and developing world.

A gap in knowledge about oral health currently exists between wealthy and poor countries. ${ }^{4}$ To improve the health of populations globally, it has been argued that biomedical research should occur in both developed and developing countries. ${ }^{6}$ Biomedical research can support economic development. ${ }^{5}$ Increasing research capacity has been described as an "effective, efficient, and sustainable method for enabling developing countries to benefit from advances in knowledge."4 Furthermore, the results from studies conducted in developed 
countries may not always apply to developing countries due to differences in disease epidemiology and resources available for healthcare. ${ }^{6}$

To assess the research contributions of countries around the world, biomedical research publication has been used as an index for health research productivity. ${ }^{6}$ Over the past decade, several studies have evaluated the quantity and quality of biomedical research publications produced around the world. ${ }^{5-11} \mathrm{Spe}-$ cific bibliometric analyses have been conducted on published research in several biomedical fields. ${ }^{7-11}$ However, there has been limited application of the technique to assess trends in global oral health research. ${ }^{12-14}$ Global trends in prosthodontic research activity have not been evaluated. Therefore, the purpose of this study was to evaluate the quantity of prosthodontic literature produced globally by continent and country in three prosthodontic journals over the 10-year period, 1998-2008. In addition, prosthodontic publication productivity in relation to economic status of countries and collaboration among countries grouped by economic status was assessed.

\section{Materials and Methods}

Three peer-reviewed prosthodontic journals were used for the analysis of articles published in 1998, 2003, and 2008: The Journal of Prosthetic Dentistry (JPD), International Journal of Prosthodontics (IJP), and Journal of Prosthodontics (JP). Three investigators (DJL, JCY, CS) reviewed all articles in each journal for the 3 years included in the study. Abstracts, letters to the editor, editorials, and book reviews were excluded from the analysis. The country of the authors listed for each included article was recorded. If an article was written by multiple authors, the document was assigned to each country of every author listed. Data were recorded and entered into a software database (Microsoft Excel 2003; Microsoft Corp., Redmond, WA).

Data were tabulated by country and continent. The continent classification (North America, Europe, Asia, South America, Africa, and Oceania [Australia and proximate Pacific Islands]) was according to Rahman and Fukui. ${ }^{6}$ The economic classification (high-income: HI; upper-middle income: UMI; lowermiddle income: LMI; and low-income: LI) of each country was obtained from the World Bank online database of World Development Indicators. ${ }^{15-17}$ Low- and middle-income countries are classified as developing countries by the World Bank. ${ }^{17}$ The quantity of publications for 1998, 2003, and 2008 was plotted by continent and economic groups. Additionally, the percentage of publications among countries classified by economic status that involved collaboration between authors of different countries was calculated.

\section{Results}

A total of 998 articles were included in the study for the years 1998, 2003, and 2008. Out of these articles, 124 were written by authors from multiple countries. Because each country represented was given a whole count for those articles, the final number of publications for this study was 1143 . The number of articles included from each journal varied by year, but in total, $55.4 \%$ of the articles were from JPD, $27.3 \%$ were from IJP, and $17.3 \%$ were from JP. Table 1 presents the economic status of each country, the total number of publications included from each journal, and the number of articles produced each year by continent and country. While the majority of the included publications from JP and JPD originated from North America (USA), the majority of the included articles published in IJP were from Europe (Sweden and Germany). With respect to countries grouped according to economic status, the most productive countries within HI, UMI, LMI, and LI countries were the US, Brazil, Turkey, and India, respectively.

Over the 10-year period, the majority of publications were produced in Asia, Europe, and North America (92.0\%). The US published the most prosthodontic articles worldwide over the study period $(38.1 \%)$. Within Asia, Japan produced the most publications overall, but Turkey more than quadrupled its production from 1998 to surpass that of Japan in 2008. Germany produced the highest number of articles in Europe, followed by the United Kingdom and Sweden. While publications doubled in Germany, production declined significantly in the UK and Sweden over the 10-year period. The majority of publications from South America originated from Brazil, which more than doubled its production over the 10 years.

Figure 1 displays the trend from 1998 to 2008 of the absolute number of publications by continent. While North America and Europe produced the most publications over the period, both continents demonstrated a negative trend between the years 2003 and 2008. Asia showed the greatest increase in absolute production over the 10-year period, matching that of Europe in 2008. While accounting for a smaller portion of total publications, South America and Africa demonstrated a positive trend in publication, where both achieved more than a twofold increase from 1998 to 2008.

In Figure 2, countries are grouped according to economic status, and the trend of publication production over time is shown. While HI countries contributed approximately $84 \%$ of the total share of publications, they demonstrated a negative trend from 1998 to 2008. UMI, LMI, and LI countries increased publication production, contributing $22.9 \%$ of the total share of publications in 2008 compared with $8.5 \%$ in 1998 . UMI countries showed the greatest growth in production, doubling the number of articles produced between 2003 and 2008.

Table 2 lists the relative number of publications by each economic group of countries where collaboration occurred among authors of multiple countries. Out of all income groups, LMI countries had the highest percentage of collaborative articles (40.6\%). In 2008, over two-thirds of publications by LMI countries were the product of collaboration. In contrast, one-third of articles by HI and LI countries resulted from collaboration. Both LI and HI countries demonstrated a positive trend in collaboration over the study period.

\section{Discussion}

In 1998, authors in North America and Europe were the most active in the production of prosthodontic publications; however, productivity declined in these two continents over the study period, while it rose by $110.6 \%$ in Asia, to equal that of Europe in 2008. Considerably fewer articles were contributed by Africa, Oceania, and South America. Europe and North 
Table 1 Number of prosthodontic publications produced by continents and countries in each economic status, by journal and by year

\begin{tabular}{|c|c|c|c|c|c|c|c|c|}
\hline & \multirow[b]{2}{*}{ Economic status } & \multicolumn{3}{|c|}{ Journal } & \multicolumn{4}{|c|}{ Year } \\
\hline & & $J P$ & $J P D$ & IJP & 1998 & 2003 & 2008 & Total \\
\hline & & n (\%) & & $n(\%)$ & & & & \\
\hline Africa & & $4(2.0)$ & $8(1.3)$ & $8(2.6)$ & $5(1.4)$ & $4(1.0)$ & $11(2.9)$ & $20(1.7)$ \\
\hline Egypt & LMI & 4 & 5 & 3 & 3 & 2 & 7 & 12 \\
\hline Nigeria & LI & 0 & 1 & 0 & 1 & 0 & 0 & 1 \\
\hline South Africa & UMI, LMI, UMI* & 0 & 2 & 2 & 1 & 0 & 3 & 4 \\
\hline Tanzania & LI & 0 & 0 & 3 & 0 & 2 & 1 & 3 \\
\hline Asia & & $36(18.2)$ & $134(21.2)$ & 65 (20.8) & $47(12.9)$ & $89(22.7)$ & $99(25.7)$ & 235 (20.6) \\
\hline China & LMI & 1 & 6 & 4 & 0 & 3 & 8 & 11 \\
\hline Hong Kong & $\mathrm{HI}$ & 0 & 4 & 1 & 1 & 3 & 1 & 5 \\
\hline Iran & LMI & 2 & 4 & 0 & 0 & 4 & 2 & 6 \\
\hline India & LI & 3 & 4 & 0 & 0 & 2 & 5 & 7 \\
\hline Israel & $\mathrm{HI}$ & 0 & 19 & 4 & 5 & 14 & 4 & 23 \\
\hline Japan & $\mathrm{HI}$ & 10 & 28 & 31 & 25 & 21 & 23 & 69 \\
\hline Jordan & LMI & 1 & 3 & 2 & 1 & 3 & 2 & 6 \\
\hline Korea & $\mathrm{HI}$ & 0 & 3 & 2 & 0 & 3 & 2 & 5 \\
\hline Kuwait & $\mathrm{HI}$ & 0 & 1 & 1 & 0 & 1 & 1 & 2 \\
\hline Lebanon & UMI & 0 & 3 & 0 & 0 & 3 & 0 & 3 \\
\hline Malaysia & UMI & 2 & 1 & 0 & 1 & 0 & 2 & 3 \\
\hline Saudi Arabia & UMI, UMI, HI* & 7 & 9 & 4 & 5 & 5 & 10 & 20 \\
\hline Singapore & $\mathrm{HI}$ & 0 & 3 & 3 & 1 & 2 & 3 & 6 \\
\hline Syria & LMI & 0 & 3 & 0 & 1 & 0 & 2 & 3 \\
\hline Taiwan & $\mathrm{HI}$ & 0 & 5 & 2 & 1 & 3 & 3 & 7 \\
\hline Thailand & LMI & 1 & 1 & 0 & 0 & 1 & 1 & 2 \\
\hline Turkey & UMI, LMI, UMI* & 8 & 37 & 8 & 6 & 18 & 29 & 53 \\
\hline United Arab Emirates & $\mathrm{HI}$ & 1 & 0 & 3 & 0 & 3 & 1 & 4 \\
\hline Europe & & $26(13.1)$ & $136(21.5)$ & 161 (51.6) & $108(29.6)$ & $116(29.5)$ & $99(25.7)$ & $323(28.3)$ \\
\hline Austria & $\mathrm{HI}$ & 0 & 3 & 3 & 2 & 3 & 1 & 6 \\
\hline Belgium & $\mathrm{HI}$ & 0 & 2 & 3 & 1 & 1 & 3 & 5 \\
\hline Croatia & UMI & 0 & 1 & 2 & 0 & 2 & 1 & 3 \\
\hline Denmark & $\mathrm{HI}$ & 0 & 1 & 2 & 2 & 1 & 0 & 3 \\
\hline Ireland & $\mathrm{HI}$ & 0 & 7 & 2 & 3 & 5 & 1 & 9 \\
\hline Italy & $\mathrm{HI}$ & 5 & 11 & 10 & 4 & 9 & 13 & 26 \\
\hline Finland & $\mathrm{HI}$ & 1 & 6 & 4 & 5 & 4 & 2 & 11 \\
\hline France & $\mathrm{HI}$ & 0 & 2 & 1 & 1 & 1 & 1 & 3 \\
\hline Germany & $\mathrm{HI}$ & 3 & 30 & 36 & 15 & 22 & 32 & 69 \\
\hline Greece & $\mathrm{HI}$ & 3 & 6 & 7 & 2 & 6 & 8 & 16 \\
\hline Hungary & UMI & 0 & 1 & 0 & 0 & 1 & 0 & 1 \\
\hline Liechtenstein & $\mathrm{HI}$ & 0 & 1 & 0 & 0 & 1 & 0 & 1 \\
\hline Netherlands & $\mathrm{HI}$ & 5 & 5 & 13 & 5 & 7 & 11 & 23 \\
\hline Northern Ireland & $\mathrm{HI}$ & 0 & 1 & 0 & 1 & 0 & 0 & 1 \\
\hline Norway & $\mathrm{HI}$ & 0 & 0 & 8 & 3 & 3 & 2 & 8 \\
\hline Poland & UMI & 0 & 3 & 0 & 1 & 1 & 1 & 3 \\
\hline Portugal & $\mathrm{HI}$ & 0 & 1 & 0 & 0 & 0 & 1 & 1 \\
\hline Spain & $\mathrm{HI}$ & 1 & 7 & 3 & 5 & 4 & 2 & 11 \\
\hline Sweden & $\mathrm{HI}$ & 1 & 10 & 38 & 25 & 19 & 5 & 49 \\
\hline Switzerland & $\mathrm{HI}$ & 0 & 8 & 7 & 6 & 6 & 3 & 15 \\
\hline UK & $\mathrm{HI}$ & 7 & 30 & 22 & 27 & 20 & 12 & 59 \\
\hline North America & & 118 (59.6) & 316 (49.9) & 59 (18.9) & $188(51.5)$ & $158(40.2)$ & 147 (38.2) & $493(43.1)$ \\
\hline Canada & $\mathrm{HI}$ & 9 & 27 & 22 & 33 & 12 & 13 & 58 \\
\hline USA & $\mathrm{HI}$ & 109 & 289 & 37 & 155 & 146 & 134 & 435 \\
\hline Oceania & & $4(2.0)$ & $7(1.1)$ & $8(2.6)$ & $6(1.6)$ & $8(2.0)$ & $5(1.3)$ & $19(1.7)$ \\
\hline Australia & $\mathrm{HI}$ & 4 & 5 & 8 & 4 & 8 & 5 & 17 \\
\hline New Zealand & $\mathrm{HI}$ & 0 & 2 & 0 & 2 & 0 & 0 & 2 \\
\hline South America & & $10(5.1)$ & $32(5.1)$ & $11(3.5)$ & $11(3.0)$ & $18(4.6)$ & $24(6.2)$ & $53(4.6)$ \\
\hline Argentina & UMI & 0 & 1 & 0 & 0 & 1 & 0 & 1 \\
\hline Brazil & UMI & 10 & 30 & 11 & 10 & 17 & 24 & 51 \\
\hline Chile & UMI & 0 & 1 & 0 & 1 & 0 & 0 & 1 \\
\hline Total & & 198 & 633 & 312 & 365 & 393 & 385 & \\
\hline
\end{tabular}

HI: high income, UMI: upper middle income, LMI: lower middle income, LI: lower income. The economic status presented did not change over the three periods of time observed, except for South Africa, Saudi Arabia, and Turkey $\left({ }^{*}\right)$. Note: The numbers reported from each country are raw numbers. 

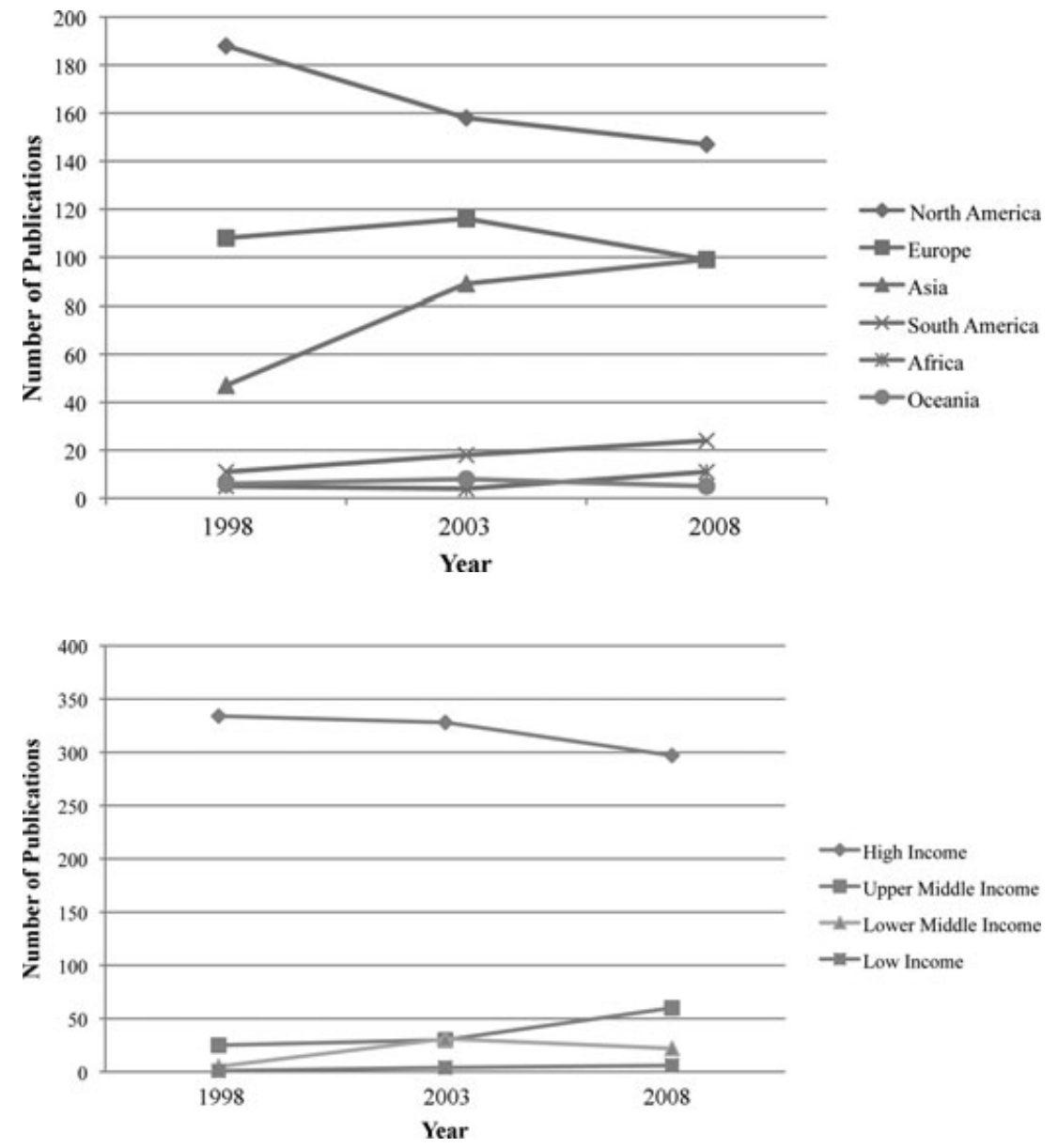

Figure 1 Trend of prosthodontic publication in different continents.
Figure 2 Trend of prosthodontic publication in countries grouped by economic status.

Table 2 Percentage of prosthodontic publications that involved collaboration between multiple countries grouped by economic classification (All UMI, LMI, and low-income countries only collaborated with HI countries)

\begin{tabular}{|c|c|c|c|c|c|c|c|c|c|c|c|c|}
\hline & \multicolumn{3}{|c|}{1998} & \multicolumn{3}{|c|}{2003} & \multicolumn{3}{|c|}{2008} & \multicolumn{3}{|c|}{ Total } \\
\hline & $\mathrm{n}_{\mathrm{c}}$ & $\mathrm{n}_{\mathrm{t}}$ & $\%$ & $\mathrm{n}_{\mathrm{c}}$ & $n_{t}$ & $\%$ & $\mathrm{n}_{\mathrm{c}}$ & $\mathrm{n}_{\mathrm{t}}$ & $\%$ & $\mathrm{n}_{\mathrm{c}}$ & $\mathrm{n}_{\mathrm{t}}$ & $\%$ \\
\hline High income & 48 & 334 & 14.4 & 74 & 328 & 22.6 & 98 & 297 & 33.0 & 220 & 959 & 22.9 \\
\hline Upper middle income & 3 & 19 & 15.8 & 6 & 30 & 20 & 10 & 60 & 16.7 & 19 & 109 & 17.4 \\
\hline Lower middle income & 4 & 11 & 36.4 & 7 & 31 & 22.6 & 15 & 22 & 68.2 & 26 & 64 & 40.6 \\
\hline Low income & 0 & 1 & 0 & 2 & 4 & 50 & 2 & 6 & 33.3 & 4 & 11 & 36.4 \\
\hline
\end{tabular}

$\mathrm{n}_{\mathrm{c}}$ : number of publications by countries of the given economic group that were the result of collaboration, $\mathrm{n}_{\mathrm{t}}$ : total number of publications by the countries of the given economic group.

America have historically led publication production in several biomedical fields. ${ }^{5-14,18}$ While some previous analyses of biomedical literature have reported relatively consistent contributions from world regions over time, ${ }^{5,6}$ others have similarly observed trends of increased production by Asia and/or decreased production by North America over the past several decades..$^{8-11,14,18-20}$ The four most productive countries in this study (US, Germany, Japan, UK) are consistent with those in bibliometric analyses of general dental and orofacial pain research. ${ }^{12,13}$ The trend toward increased authorship by Asia and although to a much smaller degree, South America and Africa, in the prosthodontic journals included in this study suggests that research within the specialty is being conducted more globally than in the past. It is difficult to ascertain whether this trend is due to globalization or other factors. While this study focused on the quantity of publications produced by continent, it would also be interesting to compare the distribution of articles submitted to the journals to those published, as it may provide insight into the quality of articles produced by different regions. 
Given that only three journals were used in this study, it is possible to consider the results with respect to the individual journals. As the total numbers of articles included from JP nearly tripled from 2003 to 2008, North America's relative contribution to this journal fell from approximately $91 \%$ in 2003 to $41 \%$ in 2008 , with a corresponding increase in the relative contributions from the other five continents. The decline in the number of articles published by North America from 1998 to 2003 resulted from a decrease in the number of articles published by this continent in JPD and IJP. Additional decline in the number of publications by North America from 2003 to 2008 corresponded to a reduction of articles in JPD. The decline in publication productivity observed in Europe from 2003 to 2008 corresponded to a decrease in the number of publications in JPD and IJP. The increased publication productivity observed in Asia reflects an increase in the number of publications in JPD and IJP from 1998 to 2003 and in JP in 2008 compared to 2003.

The results of this study also indicate that although HI countries led publication production around the world, middle- and low-income countries increasingly became more involved in the publication of prosthodontic literature over time. Research on biomedical literature published in the 1990s found highincome countries far exceeded low- and middle-income countries in research productivity. ${ }^{6}$ Similar results were found in this study; however, the positive trend in prosthodontic publication observed among middle- and low-income countries is encouraging. Gil-Montoya et al similarly found that developing countries like Turkey and Brazil demonstrated increasing numbers of dental publications. ${ }^{12}$ While productivity in LMI countries declined from 2003 to 2008, the decrease appears in large part due to a reclassification of Turkey in the World Development Indicators from lower- to upper-middle income status in 2008.

Collaboration increased within each economic classification of countries over time. Collaboration has several potential advantages, including new knowledge production, enhanced impact of research, increased creativity, and innovation. ${ }^{21}$ Lee et al demonstrated a strong association between collaboration and extramural funding in prosthodontics, suggesting another benefit of collaboration. ${ }^{21}$ This study found that in all papers resulting from collaboration among multiple countries, an $\mathrm{HI}$ country was always involved in the publication. A significant proportion of residents in US graduate prosthodontic programs are graduates of dental schools outside the US. ${ }^{22,23}$ It is possible that residents training in HI countries return to their native countries following graduation, maintaining professional ties with institutions where they studied to collaborate on projects. One may speculate that the increase in publication among middleand low-income countries observed in this study could be attributed to collaboration with HI countries; however, the results demonstrate that the majority of prosthodontic articles written by these countries were independent works.

The trends observed in this study reflect a broadening diversity in the conduct of prosthodontic research globally. Edentulism and oral disease persist worldwide and may have consequences on systemic health and quality of life, making prosthodontic therapy relevant globally. Differences in epidemiologic patterns of disease and available resources highlight the need for research in developed and developing countries. ${ }^{6}$
While information exchange between developed and developing countries is often viewed as a one-way avenue with new knowledge passing from developed to developing countries, increased research activity in developing countries can facilitate exchange in both directions. Many people in both developed and developing countries cannot afford costly prosthodontic treatments, and research conducted globally may produce novel treatment alternatives, strategies, and materials to serve all populations.

The main limitation of this study is that the data were extracted from three prosthodontic journals and, therefore, do not represent the entire body of prosthodontic literature. A previous study quantifying clinical prosthetic dentistry literature on MEDLINE in the 1990s identified 10,258 total articles published in English on the subject in over 60 journals. ${ }^{24}$ The methodology in this study likely results in an underestimation of the number of prosthodontic works written by investigators in non-English speaking countries. Research published in journals other than those included in this study certainly contributes to scientific knowledge in the field of prosthodontics. Additionally, only 3 years within the 10 -year period were analyzed. Large interannual variations of countries' publication rates have been reported in dental literature, and it is possible that the trends observed in this study do not fully account for this variability. ${ }^{12}$ However, within its limited scope, this study provides insight into the geographic origins of publications in major prosthodontic journals widely read by the profession.

\section{Conclusions}

This study evaluated the quantity of prosthodontic literature produced globally from 1998 to 2008 in three selected prosthodontic journals. The results indicated that North America (US), Europe (Germany), and Asia (Japan) were most productive in the publication of prosthodontic articles. While HI countries contributed the most prosthodontic publications, productivity increased among low- and middle-income countries in the years studied. Collaboration within HI countries, and between $\mathrm{HI}$ and the other economic classes of countries increased over time, which may indicate that the prosthodontic community is increasingly engaging in research globally.

\section{References}

1. Petersen PE: The World Oral Health Report 2003: continuous improvement of oral health in the 21 st century - the approach of the WHO Global Oral Health Programme. Community Dent Oral Epidemiol 2003 1(Suppl):3-23

2. Petersen PE, Yamamoto T: Improving the oral health of older people: the approach of the WHO Global Oral Health Programme. Community Dent Oral Epidemiol 2005;33:81-92

3. Felton DA: Edentulism and comorbid factors. J Prosthodont 2009; 18:88-96

4. Petersen PE: Priorities for research for oral health in the $21 \mathrm{st}$ century - the approach of the WHO Global Oral Health Programme. Community Dent Health 2005;22:71-74

5. Soteriades ES, Rosmarakis ES, Paraschakis K, et al: Research contribution of different world regions in the top 50 biomedical journals (1995-2002). FASEB J 2006;20:29-34 
6. Rahman M, Fukui T: Biomedical publication-global profile and trend. Public Health 2003;117:274-280

7. Falagas ME, Michalopoulos AS, Bliziotis IA, et al: A bibliometric analysis by geographic area of published research in several biomedical fields, 1995-2003. CMAJ 2006;175: 1389-1390

8. Michalopoulos A, Bliziotis IA, Rizos M, et al: Worldwide research productivity in critical care medicine. Crit Care 2005;9:R258-R265

9. Michalopoulos A, Falagas ME: A bibliometric analysis of global research production in respiratory medicine. Chest 2005;128:3993-3998

10. Rosmarakis ES, Vergidis PI, Soteriades ES, et al: Estimates of global production in cardiovascular diseases research. Int $\mathbf{J}$ Cardiol 2005; 100:443-449

11. Tas F: The contribution of countries and world regions in productivity of oncological publication. Ann Oncol 2008;19:1962-1968

12. Gil-Montoya JA, Navarrete-Cortes J, Pulgar R, et al: World dental research production: an ISI database approach (1999-2003). Eur J Oral Sci 2006;114:102-108

13. Robert C, Caillieux N, Wilson CS, et al: World orofacial pain research production: a bibliometric study (2004-2005). J Orofac Pain 2008;22:181-189

14. Kanavakis G, Spinos P, Polychronopoulou A, et al: Orthodontic journals with impact factors in perspective: trends in the types of articles and authorship characteristics. Am J Orthod Dentofacial Orthop 2006;130:516-522

15. World Bank. World Development Indicators 1998. Washington, DC, World Bank, 1998
16. World Bank. World Development Indicators 2003. Washington, DC, World Bank, 2003

17. World Bank. World Development Indicators 2008. Washington, DC, World Bank, 2008

18. Modi P, Hassan A, Teng CJ, et al: "How many cardiac surgeons does it take to write a research article?": seventy years of authorship proliferation and internationalization in the cardiothoracic surgical literature. J Thorac Cardiovasc Surg 2008;136:4-6

19. Cappell MS, Davis M: A significant decline in the American domination of research in gastroenterology with increasing globalization from 1980 to 2005: an analysis of American authorship among 8,251 articles. Am J Gastroenterol 2008;103:1065-1074

20. Stossel TP, Stossel SC: Declining American representation in leading clinical-research journals. N Engl J Med 1990;322:739-742

21. Lee DJ, Yuan JC, Knoernschild KL, et al: Research in prosthodontics: a 10-year observation of trends in topics, collaboration, and funding. Int J Prosthodont 2011;24:473-478

22. Wright RF, Dunlop RA, Kim FM, et al: A survey of program directors: trends, challenges, and mentoring in prosthodontics. Part 1. J Prosthodont 2008;17:69-75

23. Al-Sowygh ZH, Sukotjo C: Foreign-trained dentists in advanced education in prosthodontics programs in the United States: demographics, perspectives on current training, and future goals. J Prosthodont 2011;20:161-165

24. Nishimura K, Rasool F, Ferguson MB, et al: Benchmarking the clinical prosthetic dental literature on MEDLINE. J Prosthet Dent 2002;88:533-541 